
$\begin{array}{cccr}\text { Поэтому } & \text { здесь } & \text { тоже } & \text { появляется } \\ \text { необходимость проведения } & \text { расчета } & \text { интегральной }\end{array}$ оценки рациональности какой-либо исследуемой ИЛСГП экспертными методами, который может использоваться на практике в зависимости от варианта постановки задачи и требуемой точности вычислений.

\section{Литература}

1. Леонтьев Р.Г., Архипова Ю.А. Логистика горного дела (интегрированные системы) : монография..- Владивосток : Издательство Дальневост. федерал. ун-та, 2021. - 200 с.

2. Горное дело: Терминологический словарь / Под ред. К.Н. Трубецкого, Д.Р. Каплунова. - М.: Издательство «Горная книга», 2016. - 635 с.

3. Rudolf Leontiev, Alexey Barchukov and Maria Nemchaninova. Mining logistics systems: classification, identification, innovation // VIII International Scientific Conference "Problems of Complex Development of Georesources" (PCDG 2020). Volume 192 (2020). Khabarovsk, Russian Federation, September 8-10, 2020.

ИНСТИТУЦИОНАЛЬНОЕ ОБЕСПЕЧЕНИЕ ГОСУДАРСТВЕННОГО РЕГУЛИРОВАНИЯ СТРАХОВОГО ПРЕДПРИНИМАТЕЛЬСТВА В ТАДЖИКИСТАНЕ

DOI: 10.31618/ESU.2413-9335.2021.2.93.1.1555

Мирсаидов А.Б.,

доктор экономических наук, профессор, замдиректора Института экономики и демографии Национальной академии Таджикистана Шамсуллозода Ш. кандидат экономических наук, дочент кафедры управление государственными финансами Академия государственного управления при Президенте Республики Таджикистан

\title{
INSTITUTIONAL SUPPORT FOR STATE REGULATION OF INSURANCE BUSINESS IN TAJIKISTAN
}

\author{
Mirsaidov A.B., \\ Doctor of Economic Sciences, \\ professor, deputy director \\ Institute of Economics and Demography \\ National Academy of Tajikistan \\ Shamsullozoda Sh. \\ candidate of economic sciences, \\ Academy of Public Administration \\ under the President of the Republic of Tajikistan
} Associate professor of the department of public financial management

\begin{abstract}
АННОТАЦИИ
В статье анализируются тенденции роста экономики Республики Таджикистан, которые сопровождаются развитием института страхования как одного из компонентов экономической инфраструктуры. Выявлены специфические особенности страхового предпринимательства, тенденции формирования и развития институциональной структуры и высокого уровня институциональных отношений в этом виде деятельности. Обосновано, что на современном этапе развития республики государственное регулирование страховой деятельности превратилось в сложную систему регулирования, охватывающую различные блоки отношений, связанных как с созданием и использованием страховых фондов, так и с функционированием различных структур экономических институтов, которые требуют соответствующих типов институционального обеспечения регулирования.
\end{abstract}

\section{ANNOTATIONS}

The article analyzes the growth trends of the economy of the Republic of Tajikistan, which accompanied the development of the insurance institution as one of the components of the economic infrastructure. The specific features of insurance business, trends in the formation and development of the institutional structure and a high level of institutional relations in this type of activity are revealed. It is substantiated that at the present stage of the development of the republic, the state regulation of insurance activities has turned into a complex system of regulation, covering various blocks of relations, both regarding the creation and use of insurance funds, and related to the functioning of various structures of economic institutions, which requires the appropriate type of institutional provision regulation.

Ключевые слова: институт страхования, страховой сектор экономики, страховое предпринимательство, государство, государственное регулирование страховой деятельности, институциональная структура, институциональное обеспечение регулирования. 
Key words: insurance institute, insurance sector of the economy, insurance business, government, government regulation of insurance activities, institutional structure, institutional support, regulation, etc.

Рост экономики Республики Таджикистан сопровождался соответствующим развитием многих рыночных институтов, в том числе и института страхования, как одного из компонентов экономической инфраструктуры. Роль и значение страхового института все более возрастает в системе финансовых услуг, поскольку направлен на обеспечение защиты хозяйствующих субъектов от неблагоприятных событий. Спрос хозяйствующих субъектов и населения на страховую защиту объективно существует и принимает тенденции роста по мере развития экономики республики. В условиях перехода страны на стадию развивающегося рынка, основными параметрами которого являются развитие рынка финансовых услуг и активизация процессов капитализации доходов населений, что способствует росту доли дохода от бизнеса и капитала в структуре доходов населения, наблюдается тенденции роста потребности на страховые услуги. Это связано с тем, что наблюдается нестабильное развитие экономики изза возрастающего уровня неопределённости и степени риска для предприятий, предпринимателей и населения, а также возникновения новых рисков, характерных для развивающегося рынка. С целью частичного покрытия потерь, связанных с проявлением экономических рисков, многие субъекты экономики обращаются к страхованию. Как свидетельствуют данные таблицы 1, в последние семь лет, т.е. в период 2014-2020 гг., доходы страховых организаций республики увеличились от 138,3 до 256,4 млн. сомони, или более чем на 1,8 раз. Увеличение объёма доходов страховых организаций произошла, в основном, за счёт роста страховых взносов, который составляет $198,9 \%$, его доля в сумме доходов в 2020 г. составила 92,7\% против 85,4 в 2014 г. Наблюдается также увеличение объёма прочих доходов страховых организаций. Объем расходов страховых организаций увеличился с 124,8 до 174,7 млн. сомони (на 29\%). В 2020 г. доходы страховых организации расходовались всего в объёме $62,7 \%$, что по сравнению с 2014 г. ниже, чем на 27,5 процентного пункта. За анализируемый период выплаты страховых возмещений и страховых сумм уменьшились на $26 \%$, а объем отчислений в страховые резервы увеличился более чем на $56,7 \%$. Объем страховых взносов (премии), переданных на перестрахование, как важный современный компонент страховой системы и механизм капитализации доходов страховых организаций, уменьшился на 94\%. Объем отчислений в резерв для финансирования мероприятий по предупреждению несчастных случаев, утраты или повреждения застрахованного имущества увеличился с 3,2 до 12,6 млн. сомони, имеет максимальный рост - более чем на 3,9 раза. Объем расходов на ведение дела увеличился более чем на $61,5 \%$. За анализируемый период объем балансовой прибыли увеличился с 13,5 до 94,8 млн. сомони, более чем на 7 раз.

Таблица 1.

Динамика основных показателей развития страхового сектора экономики Республики Таджикистан (млн. сомони)

\begin{tabular}{|c|c|c|c|c|c|c|c|c|}
\hline Показатели & 2014 & 2015 & 2016 & 2017 & 2018 & 2019 & 2020 & $\begin{array}{c}2020 \text { к } \\
2014 \text { в } \\
\%\end{array}$ \\
\hline Доходы - всего & 138,3 & 154,3 & 131,3 & 178,0 & 235,2 & 244,9 & 256,4 & 185,4 \\
\hline \multicolumn{9}{|l|}{ из них } \\
\hline страховые взносы & 118,1 & 121,3 & 118,2 & 162,1 & 226,1 & 227,2 & 235 & 198,9 \\
\hline $\begin{array}{c}\text { прочие доходы от страховой } \\
\text { деятельности }\end{array}$ & 20,2 & 33,0 & 13,1 & 15,9 & 9,1 & 17,6 & 21,4 & 105,9 \\
\hline Расходы - всего & 124,8 & 128,9 & 122,4 & 170,6 & 193,3 & 174,7 & 161 & 129,0 \\
\hline \multicolumn{9}{|l|}{ из них: } \\
\hline $\begin{array}{c}\text { выплаты страхового возмещения и } \\
\text { страховых сумм }\end{array}$ & 25,4 & 17,6 & 17,9 & 10,8 & 10,7 & 14,9 & 18,7 & -26 \\
\hline отчисления в страховые резервы & 39,9 & 51,1 & 48,0 & 51,9 & 28,7 & 66,6 & 62,5 & 156,7 \\
\hline $\begin{array}{c}\text { страховые взносы (премии), } \\
\text { переданные на перестрахование }\end{array}$ & 13,6 & 4,5 & 10,8 & 65,9 & 61,1 & 3,0 & 0,8 & -94 \\
\hline $\begin{array}{c}\text { отчисления в резерв для } \\
\text { финансирования мероприятий по } \\
\text { предупреждению несчастных случаев, } \\
\text { утраты или повреждения } \\
\text { застрахованного имущества } \\
\end{array}$ & 3,2 & 10,0 & 2,6 & 1,1 & 3,2 & 14,0 & 12,6 & 393,7 \\
\hline расходы на ведение дела & 40,1 & 42,1 & 38,0 & 33,6 & 86,5 & 50,3 & 64,8 & 161,5 \\
\hline $\begin{array}{c}\text { прочие расходы от страховой } \\
\text { деятельности }\end{array}$ & 2,6 & 5,4 & 5,1 & 7,3 & 3,1 & 25,9 & 2,2 & $-15,3$ \\
\hline Балансовая прибыль & 13,5 & 25,4 & 8,9 & 8,3 & 41,9 & 70,2 & 94,8 & 702,2 \\
\hline
\end{tabular}

Источник: Статистический сборник Республики Таджикистан, 2021. С.691. 
Анализ основных показателей страховой деятельности показывает, что обратная связь страховых организаций со страхователями, именно которые и авансируют финансовые ресурсы для создания страхового продукта, очень слабая. Об этом свидетельствует снижение объёма выплат страхового возмещения и страховых сумм, а также доля расходов в общей сумме доходов страховых организаций. Это не означает, что тенденция снижения этих расходов происходила в результате уменьшения числа страховых случаев в экономике. Это происходило, на наш взгляд, в результате увеличения транзакционных расходов, связанных с оформлением документов, необходимых для получения страховых выплат.

Как показывают данные таблицы 1 , хотя в республике наблюдается активность деятельности страховых организации, однако объективно существующие потенциальные потребности субъектов страхования полностью не реализуются. Поэтому уровень развития страхового сектора, проникновение страховых продуктов в экономику нашей республики и в жизнь общества все ещё незначительны. Можно утверждать, что в настоящее время всего около 10\% потенциальных рисков хозяйствующих субъектов экономики покрывается страхованием. В республике доля страховых взносов в ВВП в 2020 году составляла $0,3 \%,{ }^{1}$ что меньше на 29-30 раза, чем в развитых странах (Западной Европы - 8,44\% и США - 9,2\%.)

Следует отметить, что в индустриально развитых странах субъекты страхового предпринимательства являются активными агентами рынка финансовых услуг и институциональным инвесторами в экономике, что пока ещё не получило отражение в экономике республики. Поэтому с целью обеспечения условий и среды для развития страхового предпринимательства требуется исследование его современной институциональной структуры, выявление свойственных рынку страховых услуг диспропорций.

Страховые

организации

как

специализированный агент рынка страховых услуг ведут предпринимательскую деятельность. Как подчёркивал российский ученый Д.И. Мейер, "страхование, организованное по началу взаимности, выгоднее для участников, потому что взнос, который они делают, употребляется исключительно на вознаграждение убытков... Во всяком случае остаток составляет общую собственность участников договора, тогда как при страховании страховщик старается получить возможно большую прибыль и остаток премии в любом случае составляет собственность страховщика, его барыш"3. Расширение бизнес-

\footnotetext{
1 Статистический сборник Республики Таджикистан , 2021, С. 691

2 Доля взносов в общее страхование в
} ВВП//https://sdamzavas.net/1-3773.html обращения: 17.11.2021). деятельности страховых организаций, в целом страхового предпринимательства, зависит от уровня развития страхового рынка. Но необходимо отметить, что продукт или товар, производимый и продаваемый страховым предпринимателем на рынке, отличается от других типов предпринимательства, существующих в экономике. Если обычные предприниматели (реального сектора экономики) первоначально авансируют ресурсы в процесс производства товаров и получают оплату после реализации товара покупателям, то в страховании присутствует обратный процесс. Здесь, наоборот, потребитель авансирует страховые организации для производства продукта. Потому что страховой взнос как плата за страховой продукт/услугу уплачивается в начале срока действия договора страхования. Что касается реализации страхового продукта со стороны страхового предпринимателя, то она происходит в течение длительного времени, по мере возникновения нежелантельных случаев. В этом заключается принципиальное отличие правила страхового предпринимательства от других тип предпринимательства. Кроме того, страховое предпринимательство является более институционным типом деятельности, которая имеет ряд специфических особенностей. ${ }^{4}$ Первое, предпринимательская деятельность в страховой сфере является лицензируемой. Предпринимателям данной сферы предоставляется лицензия в соответствии с Законом Республики Таджикистан "О лицензировании отдельных видов деятельности", а на отдельные виды страхования в соответствии с Законом Республики Таджикистан «O страховой деятельности). Государственный орган по надзору за страховой деятельностью в рамках названных законов при выдаче лицензии на определённые виды страховой деятельности определяет и утверждает правила организации деятельности по определённой страховой деятельности. Второе, государственный орган по надзору за страховой деятельностью регулирует и контролирует деятельность субъектов страхового предпринимательства, т.е. данный вид деятельности подлежит специальному регулированию и контролю. (Статья 22. Закона Республики Таджикистан «О страховой деятельности). Третье, в системе страхового предпринимательства действует принцип исключительности - субъекты этого сектора не имеет права заниматься производственной, торгово-посреднической и банковской деятельностью. Только специализированным страховым организациям выдают соответствующую лицензию для деятельности, а другие субъекты экономики не имеют права

${ }^{3}$ Мейер Д.И. Русское гражданское право: в 2 ч. 8му изд., исправление и дополнение 1902 г. Изд. 2-е, испр. М., 2000. С. 681.

4 Мирсаидов А.Б., Шамсуллозода Х. Инвестиционная природа страхования. Душанбе: «Ирфон», 2015 г. с.97 
заниматься страховой деятельностью. Четвёртое, деятельность страховых предпринимателей основывается на создании страховых фондов, ресурсы которых могут стать активами, создающими страховые услуги и приносящие им доходы. Пятое, деятельность субъектов страхового предпринимательства направлена на покрытие убытков, происходящих от страховых случаев и появления различного рода рисков. Поэтому страховым организациям необходимо постоянно принимать меры по пополнению страховых фондов путём привлечения клиентов и большого объёма реализации многообразных страховых продуктов. В статье 10. Закона Республики Таджикистан «О страховой деятельности» уточнены понятия «страховой агент» и «страховой брокер», как посредников при реализации страховых услуг, которые предоставляют возможность страховым организациям укрепить страховые фонды. Шестое, деятельность страховых предпринимателей сопряжена с самыми разнообразными рисками, следовательно, для оптимального и равномерного распределения этих рисков используется институт перестрахования. Это означает, что часть рисков перекладывается на другую страховую организацию. В результате этого риски равномерно распределяются по всей экономической системе.

Кроме перечисленного, существует также ряд существенных особенностей, которые связаны с особенностями формирования и развития институциональной структуры страхового сектора экономики. Например, в рамках Закона «О страховой деятельности» для страховых предпринимателей предусматривается:

- минимальный уровень уставного капитала;
- установление соотношения между активами и страховыми обязательствами; осуществление контроля над ценообразованием, т.е. контролируется процесс установления обоснованных цен на страховые услуги;

- определение правил создания и размещения страховых резервов;

- установление специальных форм учета и отчетности.

Правительства республики в рамках действующего законодательства определяет ограничение в участии иностранных страховых организаций на рынке страховых услуг страны, участие их капитале в капитала отечественных страховых организаций: устанавливает квоту участия иностранного капитала в уставных капиталах отечественных страховых организаций. Деятельность страховых предпринимателей на рынке страховых услуг состоит из следующих трансакций: заключение договоров страхование и реализация страховых услуг; сбор страховых взносов, создание фондов и размещение страховых резервов; осуществление страховых выплат (при возникновении страховых случаев); прекращение или расторжение договора страхования. Каждая из этих трансакций или процессов имеет соответствующие правила и процедуры. В настоящее время в республике функционируют 19 страховых компаний, активы которых составляли в 2020 г. 380 млн. сомони, что по сравнению с 2014 г. больше на 75\%. Размер их уставных капиталов в 2020 г. составлял 140,1 млн. сомони и по сравнению с 2014 г. увеличился на $34 \% .^{5}$

Таблица 2.

Тенденция роста страхового взноса и его структуры в Республике Таджикистан (млн. сомони)

\begin{tabular}{|c|c|c|c|c|c|}
\hline \multirow{2}{*}{ Годы } & \multirow{2}{*}{$\begin{array}{c}\text { Общая сумма } \\
\text { страховых } \\
\text { взносов }\end{array}$} & \multicolumn{2}{|c|}{ В том числе } & \multicolumn{2}{|c|}{$\begin{array}{c}\text { Доля в общем объёме } \\
\text { страхования, \% }\end{array}$} \\
\hline & & $\begin{array}{c}\text { Обязатель- } \\
\text { ное }\end{array}$ & $\begin{array}{l}\text { Добро- } \\
\text { вольное }\end{array}$ & Обязательное & $\begin{array}{c}\text { Доброволь- } \\
\text { ное }\end{array}$ \\
\hline 2010 & 106,5 & 34,0 & 72,5 & 31,9 & 68,1 \\
\hline 2011 & 130,1 & 56,6 & 73,5 & 43,5 & 56,5 \\
\hline 2012 & 134,6 & 58,2 & 76,4 & 43,2 & 56,8 \\
\hline 2013 & 135,1 & 58,3 & 76,8 & 43,2 & 56,8 \\
\hline 2014 & 118,9 & 44,8 & 74,1 & 37,7 & 62,3 \\
\hline 2015 & 121,3 & 38,4 & 82,9 & 31,7 & 68,3 \\
\hline 2016 & 118,2 & 35,4 & 82,8 & 30,0 & 70,0 \\
\hline 2017 & 162,1 & 38,4 & 123,7 & 23,7 & 76,3 \\
\hline 2018 & 226,1 & 59,7 & 166,4 & 26,4 & 73,6 \\
\hline 2019 & 227,2 & 61,8 & 165,4 & 27,2 & 72,8 \\
\hline 2020 & 235,0 & 67,9 & 167,1 & 28,9 & 71,1 \\
\hline $\begin{array}{c}\text { Изменение, по } \\
\text { сравнению с } 2010 \text { г. }\end{array}$ & 220,6 & 199,7 & 230,4 & -3 пп & 3 пп \\
\hline
\end{tabular}

Рассчитано авторами. Источник: Официальный сайт НБТ. Nbt.tj https://www.stat.tj/. (дата обращение 21.10.2021).

\footnotetext{
5 Официальный сайт НБТ. Nbt.tj (дата обращения
}

21.10.2021) 
Как свидетельствуют данные таблицы 2, наблюдается тенденция развития страхового предпринимательства в республике, потому что за анализируемый период (2010-2020 гг.) число добровольных страхователей увеличилось, что обусловило увеличение объема добровольных страховых взносов от 72,5 до 167,1 млн. сомони. Его удельный вес в общей сумме страховых взносов в 2020 г. составлял $71,1 \%$, что по сравнению с 2010 г. увеличилось на 3 процентного пункта. Темпы роста добровольных страховых взносов опережают темпы роста обязательных страховых взносов. Эффективный спрос на рынке страховых услуг проявляется именно в результате роста добровольных страхователей, что является условием и фактором развития страхового предпринимательства.

На развитие страхового предпринимательства оказало влияние создания в республике институциональных условий для развития предпринимательской деятельности. Ещё в средине 90-х гг. прошлого столетия были созданы основы формирования и развития страхового предпринимательства в нашей республике, что сопровождалось организацией новой институциональной формы коммерческого страхования. Это дало импульс дальнейшему развитию негосударственного типа страхования, увеличению числа страховых организаций. В сфере страхового сектора экономики принят Закон Республики Таджикистан «О страховой деятельности», в котором внесено изменение с учётом возникших новых отношений и тенденций развития в 2016 году. Этот закон определил институциональные основы «осуществления страхования как вида предпринимательской деятельности, особенности создания, лицензирования, регулирования, прекращения деятельности страховых (перестраховочных) организаций, страховых брокеров, условия деятельности на страховом рынке иных физических и юридических лиц, а также задачи государственного регулирования страховой деятельности и принципы обеспечения надзора за страховой деятельностью» ${ }^{6}$. Согласно данному закону, разработаны среднесрочные и долгосрочные программные документы и концепции развития страхования в республике. Эти программные документы, хотя и определили пути и направления обеспечения роста страховых взносов, однако мало внимания уделяют обеспечению качества и устойчивости страховой деятельности. Программные документы развития страхования базируются, в основном на парадигме приоритетности обязательного страхования, что определила сложившаяся структура страхового рынка. Однако анализ показывает, что в развитии обязательного страхования на страховом рынке встречаются затруднения в обеспечении качественного исполнения обязанностей при наступлении страховых событий, а также несоответствие структуры и объёма страхового рынка текущим и перспективным требованиям социально-экономического развития республики. В результате наблюдается сужение этого сегмента рынка страховых услуг.

Кроме того, на современном страховом рынке республики наблюдается неразвитость многих эффективных институтов и научно-обоснованных механизмов регулирования страхового рынка, способствующих устойчивому развитию страхового предпринимательства. Это вызывает необходимость разработки институциональных технологий регулирования институтов развития, обеспечивающих эффективное функционирование субъектов страхового предпринимательства и агентов страхового рынка страны. В действительности, в настоящее время наблюдается несовершенство системы регулирования страховой деятельности, прежде всего институционального обеспечения регулирования. В отечественной экономической литературы отсутствуют специальные фундаментальнее исследования, посвящённые вопросам институционального обеспечения или институциональных основ регулирования страховой деятельности. Более того, недостаточно исследованы механизмы, обеспечивающие оптимальное соотношение между государственным и рыночным регулированием страховой деятельности.

Следует подчеркнуть, что функционирование любой социально-экономической системы, основывающихся на действии базовых рыночных институтов, институт страхования выступает в качестве неотъемлемого составного элемента институциональной структуры экономики. Страхование как рыночный институт социальноэкономического развития страны призван обеспечить социальную стабильное, стабильную развитие общественного воспроизводства и воспроизводственных процессов в хозяйствующих субъектах экономики. В связи с этим различные аспекты функционирования института страхования в экономической системе всегда имеет место в фокусе теоретических и прикладных экономических исследований. Последние годы все более возрастают роль и значение институционального подхода к объяснению понятия «страхование». В рамках этого подхода исследуется институциональная и организационная структура страховой деятельности в экономике. Страхование как институциональное понятие можно рассматривать как упорядоченные связи между различными субъектами и объектами страховых отношений, связанных с формированием денежных фондов, которые направляются на финансовую защиту имущественных интересов субъектов экономики. Институциональный подход к исследованию содержания и структуры страховых отношений 
позволяет более конкретно структурировать страховую деятельность и выработать эффективный механизм ее регулирования.

Однако по причине отсутствия в условиях перехода экономики республики на новый этап развития адекватного институционального обеспечения системы регулирования страховой деятельности наблюдаются тенденции ослабления деятельности страховых организаций, их банкротств и отзыва лицензий. Незавершённость формирования нормативно-правовой базы и институтов рынка страховых услуг, а также слабость состояния формирования и развития конкурентной среды и т.д. стали причиной болезненности трансформации страхового сектора республики на стадии развивающегося рынка. Это требует необходимости осуществления институциональных преобразований по формированию новых «правил игры» стратегического характера, создания институтов, способствующих совершенствованию институциональной структуры страхового сектора экономики, адекватных параметров развивающегося рынка. Иными словами, развитие предпринимательства в страховом секторе экономики возможно только при наличии соответствующего институционального обеспечения. Институциональное обеспечение включает в себя совокупность норм и правил действия, институты и механизмы передачи информации, организационную структуру и т.д., которые упорядочивают страховые отношения, и тем самым становятся средством регулирования. ${ }^{7}$ Институциональная структура страховой системы, которая определяет формы и виды страхового предпринимательства, состоит, прежде всего, из институтов коммерческого, социального, обязательного и добровольного страхования, которые регламентированы общими и особыми правилами.

На современном этапе развития республики государственное регулирование страховой деятельности превратилось в сложную систему регулирования. Государственное регулирование, как сложное экономическое явление, интегрирует в страховую систему и страховое предпринимательство комплекс функционирующих институтов, структурирующих страховые отношения и интересы. Система государственного регулирования страховой деятельности как разноплановый сложный объект должен иметь соответствующий институциональный механизм обеспечения двух блоков отношений: а) системы специфических социально-экономических отношений, связанных с созданием и использованием страховых фондов; б) системы отношений и взаимодействия различных структур или сложной структуры функционирующих экономических институтов.

7 Мирсаидов А.Б Институциональное проектирование в системе прогнозирования и планирования социально-экономического развития
Под систему государственного регулирования подпадают все аспекты взаимодействий агентов страхового рынка. На рынке функционирует группа участников, которые имеют прямое отношение к страховым трансакциям (страхователи, страховые организации, страховые посредники). Страховые организации как страховые предприниматели вступают в систему взаимодействий с финансовыми посредниками и субъектами инфраструктуры, которые обслуживают страховой рынок. С точки зрения государственного регулирования, в системе страховых отношений активно участвует также институты государственной власти, представители исполнительной власти - органы страхового надзора.

Реализация стратегических целей и задач экономической политики должна стать ключевым моментом государственного регулирования страхового предпринимательства на уровне макроэкономики. На современном этапе развития экономики республики наблюдается процесс включения страхового сектора и страхования рынка республики в мировое страховое пространство. Это вызывает необходимость выбора эффективной модели регулирования страхового рынка, имеющего адекватную институциональную структуру. В результате влияния глобализационных процессов на страховую систему республики наблюдается все большее стирание различий между национальной и мировой страховыми системами, которое способствует формированию общих свойств и тенденции развития. Эффект глобализации, наблюдаемый на страховом рынке, связан с тем, что эта сфера входит в финансовый сектор экономики. В данном секторе по сравнению с отраслями реального сектора существует более высокий уровень мобильности инвестиционных ресурсов, капитала, финансовых инструментов и их маневренности. Страховой сектор экономики республики относится к категории развивающихся. Поэтому модели его регулирования ещё находятся в стадии приспособления к основным мировым тенденциям. Обеспечение совершенствования механизма регулирования требует разработки новой концепции развития страхового предпринимательства и государственного регулирования с соответствующей институциональной базой, институциональной структурой, состоящих из системы взаимосвязи совокупности формальных правил и норм, определяющих «правила игры» на страховом рынке и механизмы контроля соблюдения этих правил.

В республике в настоящее время принято общее и отраслевое законодательство, определяющее институциональные основы регулирования страхового предпринимательства,

региона// Известия Академия Республики Таджикистан. Отделение общественных наук. 2017. № 1. C.43-52. 
которые становятся предпосылкой дальнейшей его корректировки и совершенствования. Пакет существующих законодательных актов можно разделить на общие и по сферам деятельности: В рамках общего законодательства (предпринимательское право, налоговое право, антимонопольное регулирование) государственное регулирование страхового предпринимательства осуществляется при помощи традиционных форм и методов, применяемых во всех сферах экономики. Но здесь учитывается специфика страховой деятельности и предпринимательства в страховом секторе экономики. В отличие от общего, отраслевое законодательство изначально отражает в себе особенности регулируемой отрасли или сферы деятельности. Оно определяет матрицу, или рамочные условия, функционирования субъектов страхового предпринимательства. Однако встречается ряд противоречивых положений между этими группами законодательных актов, поэтому в дальнейшем необходимо уделять внимание обеспечению диалектической связи этих групп законодательных актов, потому что общее и отраслевое законодательства, взаимно дополняя друг друга, максимально охватывают в себе все аспекты экономических отношений, реализуемых в страховом секторе экономики.

Как было выше отмечено, страховой сектор экономики республики испытывает на себе влияние глобализационных процессов, в связи с этим наблюдается тенденция вовлечения отечественных страховых организаций в международные интеграционные процессы. Поскольку интеграционные экономические процессы, идущие на мировом и региональном уровнях, включают в себя и страховую деятельность, страховые компании республики стремятся функционировать в составе крупных мировых страховых компаний, сферой деятельности которых являются территории различных стран мира. В этих условиях, прежде всего, необходимо обеспечить институциональную среду развития отечественного страхового рынка и страхового предпринимательства на основе гармонизации и унификации национальных законодательств или установление (без изменения национального законодательства) режима наибольшего благоприятствования для иностранных страховых компаний. В настоящее время в страховом секторе экономики республики возникла потребность в «трансплантации» институтов и выборе модели государственного регулирования страхового рынка с соответствующей институциональной структурой, апробированной в развитых странах мира. Это способствует активизации процессов вхождения отечественных страховых организаций в мировые интегрированные образования. В мировой системе государственного регулирование страховой деятельности различают «англоамериканскую» и «германскую» модели. В страховой системе Республики Таджикистан, на наш взгляд, целесообразно использовать германскую модель регулирования, для которой характерен высокий уровень государственного регулирования финансового рынка, особенно в отношении страховых организаций и страхового предпринимательства, базирующегося на сочетании государственно-рыночного механизма регулирования. Оптимальное сочетание государственных и рыночных институтов должно стать ключевым направлением регулирования страхового предпринимательства, что способствует созданию эффективной модели государственного регулирования страховой системы. Очень важно, чтобы развитие модели было ориентировано на использование современных методов государственного регулирования, которые не блокируют применение критериев экономической и социальной эффективности. ${ }^{8}$

\section{Литература:}

1.Доля взносов в общее страхование в ВВП//https://sdamzavas.net/1-3773.html (дата обращения: 17.11.2021).

2.Закон Республики Таджикистан «О страховой деятельности» от 23 июля 2016 года №1349. C. 2

3.Майер Д.И. Русское гражданское право: в 2 ч. 8-му изд., исправление и дополнение 1902 г. Изд. 2-е, испр. М., 2000. С. 681

4.Мирсаидов А.Б., Шамсуллозода Х. Инвестиционная природа страхования. Душанбе: «Ирфон», 2015 г. с.97

5.Мирсаидов А.Б Институциональное проектирование в системе прогнозирования и планирования социально-экономического развития региона// Известия Академия Республики Таджикистан. Отделение общественных наук. 2017. № 1. C.43-52. ${ }^{1}$

6. Официальный сайт НБТ. Nbt.tj (дата обращения 21.10.2021

7.Статистический сборник Республики Таджикистан , 2021, С. 691
${ }^{8}$ Гомелля, В. Б. Проблемы современного государственного регулирования страхового рынка России // Финансы. 2011. № 8. С. 50-52. 